\title{
Elevated Blood Pressure Among Zimbabwean Urban Primary School Children Aged 5-11 Years
}

\author{
Dube Adiele $^{1}$, Gundani Patrick Dube Morgan ${ }^{2}$ \\ ${ }^{1}$ Department of Emergency Medical Care, Emergency Medical Ambulances Services, Kwekwe, Zimbabwe \\ ${ }^{2}$ Department of Sports Science and Coaching, Faculty of Applied Sciences, National University of Science and Technology, Bulawayo, \\ Zimbabwe
}

\section{Email address:}

adieledube@yahoo.com (D. Adiele)

\section{To cite this article:}

Dube Adiele, Gundani Patrick Dube Morgan. Elevated Blood Pressure among Zimbabwean Urban Primary School Children Aged 5-11 Years. American Journal of Pediatrics. Vol. 3, No. 5, 2017, pp. 51-57. doi: 10.11648/j.ajp.20170305.15

Received: February 13, 2017; Accepted: April 1, 2017; Published: October 23, 2017

\begin{abstract}
Following few publications available with data on blood pressure profiles of Zimbabwean population, especially children and adolescents, few data exist on urban and rural school going children. The aims of this study were to examine the incidence of hypertension (HT) among Zimbabwean urban children residing in Kwekwe; and to determine the relationship between body mass index (BMI) and blood pressure (BP) among them. The study involved 480 primary school children (230 boys and 250 girls) aged 5-11 years. Stature and body weight were measured using standard procedures. BMI for gender and age defined overweight. BP was monitored for thrice consecutively using validated electronic devices (Omron 7051T). HT was determined as the average of three separate BP readings where the systolic or diastolic blood pressure was $\geq 95$ th percentile for age and sex. The incidence of overweight among the girls (3.6\%) was higher compared with the boys $(2.7 \%)$. Both systolic and diastolic pressures (SBP and DBP) increase with age in both sexes. Potential development of hypertension among the children is noticeable at Early Childhood Development (ECD) level for both boys and girls; $1.8 \%$ and $1.5 \%$ respectively and ranged from $0.8 \%$ to $1.8 \%$ for boys and $2.0 \%$ to $5.3 \%$ for girls. The overall incidence of hypertension was $1.5 \%$ and $2.6 \%$ in boys and girls, respectively. The highest noticeable value for boys was at ECD and decreased with increase in grade level. The incidence of hypertension (SBP $>95$ th percentile) was $0.4 \%$ and $0.2 \%$ in boys and girls, respectively. For the girls there was a progressive increase in the tendency towards development of hypertension from ECD to $6^{\text {th }}$ grade except a small decrease in $3^{\text {rd }}$ and $4^{\text {th }}$ grade levels. Girls in the $6^{\text {th }}$ grade level showed the highest value of incidence of hypertension (5.3\%). The blood pressures (SBP and DBP) significantly correlated with age, stature, body mass and BMI $(P<0.05)$. The findings demonstrate that elevated blood pressure is prevalent among urban Zimbabwean children and that there is need for routine measurement of BP to children residing in this region as part of physical examination for physical activity in schools. The use of BMI cutoffs tailored to metabolic risks may be vital for assessment of overweight. BP increased with age in both sexes, and this significantly correlated with age, stature, body weight and BMI.
\end{abstract}

Keywords: Overweight, Body Mass Index, Blood Pressure, Mining Industry, Urban Children, Zimbabwe

\section{Introduction}

The prevalence of high blood pressure in children is increasing worldwide, largely, but not entirely, driven by the concurrent childhood obesity epidemic [1]. In Zimbabwe blood pressure (BP) measuring is not regularly employed in various health check-up programmes hence studies pertaining to blood pressure of school going Zimbabwean children are still inadequate. Studies of children's BP provide important epidemiological information which may help in scheming and modifying coronary risk factors [2]. High BP levels should be associated with this high obesity prevalence estimation [1], high risk of developing of cardiovascular diseases (CVDs); including coronary heart disease (CHD), congestive heart failure (CHF), ischemic and hemorrhagic stroke, renal failure, and peripheral arterial disease and stroke in adulthood [3], [4], [5]. Therefore, it is of paramount importance to be aware of hypertension and effectively treat it during childhood and adolescence. Children and adolescents with blood pressure 
greater than the $90^{\text {th }}$ percentile for a given age have roughly a threefold greater likelihood of becoming adults with hypertension compared to those whose blood pressure is at or below the 50th percentile [6]. In addition to are also known to

BP levels track from childhood to adulthood [1], and routine pediatric examination and monitoring these levels has consistently lead to the unearthing of a considerable number of children with asymptomatic hypertension HT [7]. Literature reveals that there overweight is strongly associated with elevated BP in children and adolescents and has caused increasingly concern with monitoring arterial BP in children [1], [8], [9], [10], [11], [12]. Environmental and hereditary factors are associated with HT among children and adolescents such as age, gender, height, weight and body mass index, body size and shape, obesity, change in dietary habits and family history of hypertension, decreased physical activity, increased stress, race, ethnicity and socio-economic status influence blood pressure levels in childhood and adulthood [12], [13], [14].

In Zimbabwe, levels of overweight and obesity among children and adolescents are increasing. Studies contacted comparing data by the International Obesity Task Force (2005) and Institute for Health Metrics and Evaluation (2010; 2010) Surveys in 2002, 2010 and 2013 indicates upward trend in the level of overweight and obesity among the Zimbabwean children and adolescents [15]. The study revealed that in 2002 males and females aged 5-14 who were overweight were $15.3 \%$ and $15.4 \%$ respectively. Among the children aged 5-9 years, males overweight rates increased from $17.0 \%$ in 2010 to $19.0 \%$ in 2013 ; among females, overweight rates maintained $11.0 \%$ in 2013 to $11.0 \%$ in 2013 Also revealed was that among adolescents; the males overweight rates increased from $4.3 \%$ in 2010 to $4.4 \%$ in 2013; among females, overweight rates were maintained at $19.0 \%$ in 2010 to 2013 . Obesity and overweight can autonomously or interrelate to contribute to elevated blood pressure or hypertension among children and adolescents [12], [4], hence long-term health risks for hypertensive children and adolescents can be substantial. These findings are expected, given that Zimbabwe is undergoing socio-economic transformation, with increasing urbanization, dollarization coupled with attendant lifestyle habits that tend to promote sedentariness and patronage of fast-food restaurants [16]. Overweight and obesity possibilities among children are inevitable, therefore, it is important that measures be taken to reduce these risks and optimise health outcomes.

The American Heart Association recommends that all children aged 3 years and older should have yearly blood pressure measurements [17]. However in Zimbabwe, scanty data exist on BMI and BP in children in the above mentioned age group. Due to implications of high blood pressure in adulthood dating back to childhood, this study examines the relationship between BMI and BP in primary school children in Kwekwe urban. Having studies of this nature will also add knowledge of the dangers of overweight, obesity, and high blood pressure among children of miners and manufacturers, thereby providing intervention strategies to prevent risk factors of life associated with high blood pressure in children.

\section{Methods}

\subsection{Sampling}

A cross-sectional study was carried out among school children aged between 5 to 11 years. This was carried out from September to November 2014 using a simple ballot system to select participants from ECD to $6^{\text {th }}$ grade. Also, using the official class registers, a stratified random sample of children was drawn from each class according to their age category and gender. Children who had no mental and physical challenges or those with no history of cardiovascular, renal and endocrine diseases that could impair anthropometric measurement were included. Only those who were present on the day of measurement were measured. The sample size totaled to 480 school children of which 230 were boys and 250 were girls, residing in Kwekwe. The participants were selected from a former group A school with both boarding and day school facilities. The school was purposively selected due to its catchment area, logistical problems and was more feasible to conduct the research at this school with the assistance of Sport Science students at the National University of Science and Technology (NUST). The pupils have mixed socio-economic background. The population mainly relies on mining and manufacturing. In the late 1990 s very skimpy financial support from parents/ guardians of the school children was experienced due to economic hardships which resulting in companies scaling down its employees and production.

Consent was obtained from the parents and guardians of the children to enroll into the study. The study was approved by the National University of Science and Technology (NUST) and an approval from the Ministry of Primary and Secondary Education was obtained before the study was carried out. The children were asked to fill the demographic section of the data form indicating their class, age and gender.

Three trained research assistants, of which two who were final-year students at NUST and one practicing general nurse participated in the data collection. The research assistants have a specialized training in anthropometric and blood pressure measurements. All measurements included in the study were conducted between $1100-1300$ hours in the school hall. For reliability and accuracy in blood pressure measurements all children were requested to rest for 10 minutes in the examination room. The following measurements were recorded; height, weight, systolic blood pressure (SBP), and diastolic blood pressure (DBP). For blood pressure, a subject was measured in sitting position with the subject's right hand resting on the examining table. The blood pressure measurements were taken at the right arm for consistency. Data analysis was done using SPSS version 20.0 software.

\subsection{Measures}

BP was monitored and measured three consecutive times using the standard procedure at 5 minutes interval with a 
validated electronic devices (Omron 7051T). The average of three separate BP readings was considered to be the subject's BP. Hypertension (HT) was defined as Systolic Blood Pressure (SBD) or Diastolic Blood Pressure (DBP) exceeding the 95th percentile for age, gender, and height [45]. Hypertension was defined as blood pressure $\geq 140 / 90 \mathrm{mmHg}$, hence $\geq 90^{\text {th }}$ percentile for age and sex.

Seca 220R telescopic stadiometer was used to measure height to with a precision of $1 \mathrm{~mm}$. Weight was measured using Seca 710R weighing scale, calibrated beforehand (capacity: 200kg; precision: 50g.) All measurements were taken according to the standard procedures suggested by the International Society for the Advancement of Kinanthropometry (ISAK) [18]. Body mass index (BMI) was calculated as weight in kilograms divided by squared height in meters. International recommended BMI categorized as $<18.5$ $\mathrm{kg} / \mathrm{m}^{2}$ (lean), $18.5-24.9 \mathrm{~kg} / \mathrm{m}^{2}$ (normal), $25.0-29.9 \mathrm{~kg} / \mathrm{m}^{2}$ (over weight), and $30+\mathrm{kg} / \mathrm{m}^{2}$ (obese) for both boys and girls based on age were applied to the data and [19].

\subsection{Data Analysis}

All results were presented and expressed as $M \pm S D$ and 95\% confidence intervals (CI). Descriptive data was computed using a Statistical Package in Social Sciences (SPSS) version 20.0. The parametric t-test was used for comparisons of these variables stratified by gender. To determine the relationship between BP and anthropometric parameters, the Pearson correlation coefficient was applied. The level of statistical significance was set at $p \leq 0.05$.

\section{Results}

Table 1 below presents the body mass, stature, BMI, body fat and blood pressure (SBP and DBP) of the participants according to age and gender. The mean age of the participants was $7.7 \pm 1.9$ years. There was no significant difference found for age between boys and girls $(P=0.201)$. Table 1 below shows anthropometric and blood pressure measurements of the participants. There were no significant differences $(p \leq$ 0.05 ) despite gender differences in all the variables (age, body weight, stature, BMI, systolic blood pressure, diastolic blood pressure) measured.

Table 1. Mean and standard deviation (sd) for anthropometric measurements.

\begin{tabular}{lllll}
\hline & Boys $(\mathbf{N}=\mathbf{2 3 0})$ & Girls $(\mathbf{N}=\mathbf{2 5 0})$ & Combined $(\mathbf{N}=\mathbf{4 8 0})$ & \\
\hline Variable & Mean \pm SD & Mean \pm SD & Mean \pm SD & 95\% CI \\
\hline Age $($ yr) & $7.7 \pm 1.9$ & $7.5 \pm 1.5$ & $7.6 \pm 1.7$ & $7.5-7.9$ \\
Body mass $(\mathrm{kg})$ & $28.5 \pm 10.5$ & $33.2 \pm 10.2$ & $30.9 \pm 10.4$ & $28.5-34.7$ \\
Height $(\mathrm{cm})$ & $123.4 \pm 5.3$ & $131.7 \pm 5.8$ & $126.7 \pm 5.6$ & $127.7-132.1$ \\
BMI $\left(\mathrm{kg} / \mathrm{m}^{2}\right)$ & $19.8 \pm 6.0$ & $21.5 \pm 5.3$ & $20.7 \pm 5.6$ & 0.486 \\
SBP $(\mathrm{mmHg})$ & $92.6 \pm 9.6$ & $93.4 \pm 9.4$ & $93.0 \pm 10.0$ & $18.7-20.6$ \\
DBP $(\mathrm{mmHg})$ & $56.4 \pm 6.3$ & $56.1 \pm 6.9$ & $56.3 \pm 6.6$ & $91.8-94.2$ \\
\hline
\end{tabular}

$C I=$ Confidence Interval; $S D=$ standard deviation; $B M I=$ Body mass index; $S B P=$ Systolic blood pressure $D B P=$ Diastolic blood pressure

Table 2. Systolic and diastolic blood pressure of the participants according to age groups.

\begin{tabular}{|c|c|c|c|c|c|c|c|c|c|c|c|c|}
\hline \multirow[b]{2}{*}{$\begin{array}{l}\text { Age } \\
(y r)\end{array}$} & \multirow[b]{2}{*}{ Boys } & \multirow[b]{2}{*}{ Girls } & \multicolumn{4}{|c|}{ Systolic blood pressure (mmHg) } & \multirow[b]{2}{*}{$P$-value } & \multicolumn{5}{|c|}{ Diastolic blood pressure (mmHg) } \\
\hline & & & $\begin{array}{l}\text { Boys } \\
(\text { Mean } \pm \text { SD) }\end{array}$ & $95 \%$ CI & $\begin{array}{l}\text { Girls } \\
(\text { Mean } \pm \text { SD })\end{array}$ & $95 \%$ CI & & $\begin{array}{l}\text { Boys } \\
(\text { Mean } \pm \text { SD) }\end{array}$ & $95 \% \mathrm{CI}$ & $\begin{array}{l}\text { Girls } \\
(\text { Mean } \pm \text { SD })\end{array}$ & $95 \% \mathrm{CI}$ & $P$-value \\
\hline 5 & 35 & 40 & $83.5 \pm 4.7$ & $80.8-85.0$ & $80.3 \pm 5.8$ & $79.7-93.9$ & 0.145 & $50.4 \pm 6.2$ & $46.7-54.4$ & $50.4 \pm 3.7$ & $46.6-54.3$ & 0.623 \\
\hline 6 & 30 & 35 & $85.5 \pm 6.6$ & $81.0-89.1$ & $81.6 \pm 9.6$ & $80.8-90.5$ & 0.435 & $51.1 \pm 6.6$ & $47.4-55.6$ & $51.4 \pm 4.3$ & $47.2-53.9$ & 0.812 \\
\hline 7 & 32 & 36 & $87.5 \pm 7.1$ & $84.3-91.2$ & $82.9 \pm 9.9$ & $83.8-91.9$ & 0.638 & $52.7 \pm 6.2$ & $48.3-56.9$ & $52.0 \pm 3.9$ & $48.0-54.2$ & 0.704 \\
\hline 8 & 34 & 33 & $92.0 \pm 8.4$ & $88.7-95.2$ & $87.5 \pm 7.6$ & $86.4-93.2$ & 0.485 & $55.6 \pm 5.3$ & $49.6-57.0$ & $52.6 \pm 5.8$ & $49.7-54.7$ & 0.821 \\
\hline 9 & 31 & 34 & $92.8 \pm 10.6$ & $89.0-96.7$ & $93.0 \pm 7.3$ & $87.8-95.0$ & 0.822 & $56.4 \pm 5.3$ & $54.9-59.9$ & $54.5 \pm 4.2$ & $54.1-57.1$ & 0.304 \\
\hline 11 & 34 & 36 & $95.0 \pm 8.0$ & $90.0-10.4$ & $96.8 \pm 7.8$ & $92.4-99.6$ & 0.402 & $58.1 \pm 5.2$ & $54.7-61.6$ & $58.0 \pm 5.2$ & $55.3-60.4$ & 0.789 \\
\hline
\end{tabular}

*Statistically significant $(P \leq 0.05) ; \mathrm{CI}=$ Confidence Interval

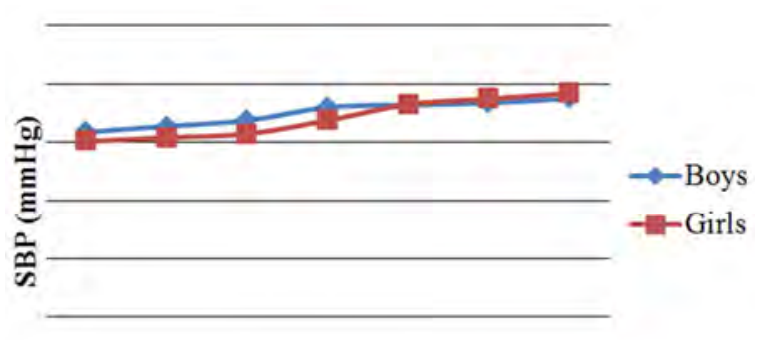

Age (yrs)

Figure 1. Variations in Systolic blood pressure of the participants according to age and gender.

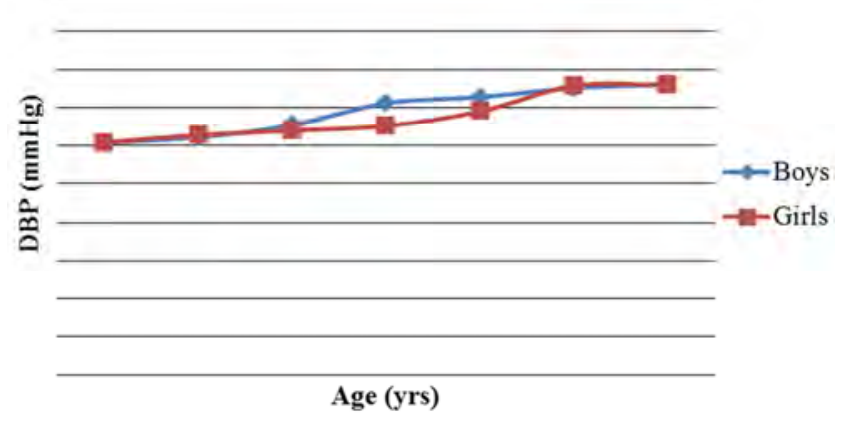

Figure 2. Variations in Diastolic blood pressure of the participants according to age and gender. 
Considering Table 1 and Table 2 results above, SBP and DBP of the participants according to age and gender indicate a steady increase with age. Table 2 shows clearly that SBP and DBP increased simultaneously with age in both sexes. There was no significant difference $(\mathrm{p} \leq 0.05)$ in both boys and girls at all ages.

Table 3. Pearson correlation analysis: Relationship of systolic and diastolic blood pressure with age, stature, body mass and body mass index.

\begin{tabular}{lllll}
\hline & \multicolumn{2}{l}{ SBP (mmHg) } & \multicolumn{2}{l}{ DBP $(\mathbf{m m H g})$} \\
\hline Variable & R & P-value & R & P-value \\
\hline Age $(\mathrm{yrs})$ & 0.120 & 0.005 & 0.080 & 0.018 \\
Body mass $(\mathrm{kg})$ & 0.400 & 0.000 & 0.350 & 0.001 \\
Stature $(\mathrm{cm})$ & 0.360 & 0.000 & 0.300 & 0.000 \\
BMI $\left(\mathrm{kg} / \mathrm{m}^{2}\right)$ & 0.320 & 0.000 & 0.310 & 0.010 \\
\hline
\end{tabular}

$\mathrm{BMI}=$ Body mass index; $\mathrm{SBP}=$ systolic blood pressure; $\mathrm{DBP}=$ diastolic blood pressure

Table 3 shows that SBP and DBP pressures significantly $(P<0.05)$ correlate with age, body weight, height and BMI.

Table 4. Incidence of Elevated blood pressure and overweight in the Kwekwe urban children.

\begin{tabular}{lllllll}
\hline \multicolumn{3}{c}{ Elevated blood pressure* } & \multicolumn{3}{c}{ Overweight $\dagger$} \\
\hline \multicolumn{3}{l}{ Gender (N) } & Boys & Girls & Boys & Girls \\
\hline Grade & Boys & Girls & \% & \% & \% & \% \\
\hline ECD & 35 & 40 & 1.5 & 1.8 & 0.1 & 0 \\
1 & 30 & 35 & 1.5 & 2 & 0.3 & 0.9 \\
2 & 32 & 36 & 1.4 & 2.5 & 1.3 & 2.1 \\
3 & 34 & 33 & 1.2 & 2.1 & 2.3 & 2.6 \\
4 & 31 & 34 & 0.9 & 1.6 & 2.8 & 2.8 \\
5 & 34 & 35 & 0.8 & 4.3 & 2.1 & 2.9 \\
6 & 34 & 36 & 1.6 & 5.3 & 2.6 & 4.5 \\
Total & 230 & 250 & 1.5 & 2.6 & 1.7 & 3.6 \\
\hline
\end{tabular}

* The average SDP and DPB was determined as $\geq 95$ th percentile for age and sex were measured on at least three separate occasions.

$\dagger$ Internationally recommended BMI cut-off points in children (Cole et al 2000).

Table 4 above presents the distribution of the incidence of hypertension and the prevalence of overweight among the children according to sex and age. The percentage of children who were overweight were higher in girls $(3.6 \%)$ compared with the boys $(2.7 \%)$.

\section{Discussion}

The present study presents the blood pressure profiles of urban school children attending primary schools in Kwekwe, a giant mining city at the heart of Zimbabwe. Literature on population -based epidemiological show that primary HT is more common among apparently healthy children [20]. High blood pressure is simply an elevated pressure of the blood in the arteries [21]. A finding from this study demonstrates elevated BP among school children which is not a new phenomenon among children in the Southern Africa region. Several similar studies conducted in South Africa, Zambia Nigeria, USA and Spain; [1], [13], [22], [23], [24], [25], [26], [27], among children and adolescents and elsewhere [28], [29], [30], [31], [32] have confirmed the presence of hypertension among children and adolescents of similar ages. High blood pressure is a major risk factor for chronic diseases, heart diseases and stroke in adulthood, [4]. The incidence of hypertension in boys and girls was $1.5 \%$ and $2.6 \%$, respectively. The values vary among the grade levels, the highest being $4.5 \%$ and $5.3 \%$ in girls at grade levels 5 and 6 , respectively. The presence of elevated BP found among the children in this region is worrisome. Although overweight occur more in girls $(3.6 \%)$, boys were found to be have higher levels of elevated BP at ECD (1.8\%), compared to girls in the same class.

Systolic BP among female students was significantly higher than male students; this is inconsistent with the result of another study [33], but it is in the same line with the results from another study [34]. The reason for the difference between the prevalence of elevated blood pressure in this study and those in the previous studies might be the usage of different age groups, impact of the geographic zone, earlier puberty in girls than boys, therefore results for elevated BP in girls may be due to puberty hormones, methods and definitions of blood pressure, and differences in reported prevalence and risk estimates [35], [36], [37], [44]. However, the high prevalence of HT in girls compared with boys might not be unconnected with the social and cultural lifestyle of females who are expected to stay at home and attend to domestic responsibilities [13], [38]. Due to several factors which might cause elevated BP, early detection of high BP by regular monitoring of the children is essential, to improve the children health care.

Lifestyle behaviours such as physical and sedentary behaviour may well account for gender differences in elevated BP among children, researchers concluded that preschool-aged children (ECD) boys were more likely to engage in moderate-to-vigorous physical activity than girls, therefore we anticipate that boys should be more physically active compared to their counterparts girls [16], [33], [39], [44]. Gender differences in the elevated BP among children were influenced by several factors associated with age, weight, height and BMI in the children. Similar findings have been reported elsewhere [24], [27], [31], [40], [41], [17], [44]. A direct relationship between high $\mathrm{BP}$ in childhood and subsequent development of the metabolic syndrome in adulthood has been observed [10], [42]. This emphasizes the need to screen and monitor children's weight and BMI of in order to safeguard their future health.

The likelihood of the development of elevated blood pressure among the children is noticeable at Early Childhood Development (ECD) level for both boys and girls $(1.8 \%$ and $1.5 \%$ respectively. The highest noticeable value for boys was at ECD and decreased with increase in grade level. This result is unusual, in the same line; other studies have reported that both sexes, overweight increases with age, declining at age 10 in boys. The reverse should be the case. For the girls there was a progressive increase in the tendency towards development of hypertension from ECD to $6^{\text {th }}$ grade except a small decrease in $3^{\text {rd }}$ and $4^{\text {th }}$ grade levels. Girls in grade level 6 showed the highest value of incidence of hypertension (5.3\%). 
The sampled population does not represent the children in Kwekwe district, nor is it reflective of the province, or national level. Those children who participated and have elevated BP are at risk of overweight. Girls were more inclined to hypertension than boys particularly in 5 th and $6^{\text {th }}$ grade levels. Finally, to detect hypertension as a risk factor in children, routine screening as well as promoting educational programs on healthy lifestyles would be beneficial.

This study has some limitations that should be noted.

a) The current study cross-sectional design, hence researchers could not make cause-effect influences.

b) The current researchers used validated electronic devices Omron 7051T and not an automatic oscillometric monitor validated for children in accordance with the Fourth Report, the recommended measurement of BP should be performed using an auscultatory method [43].

c) Measurements obtained in schools setting could have influence BP values due to the difficulties that sometimes exist in maintaining calm and conducive environment [1].

\section{Conclusion}

The study current avows the incidence of elevated blood pressure among urban primary school children in Kwekwe, Zimbabwe. The findings are consistent with other preceding studies. There was a positive correlation of BMI, body weight, height and age of the boys and girls. Early puberty and physiological changes affect more in girls than boys. Given the role of socio-economic and cultural factors underlying obesity, decreased mobility and increased blood pressure in children, it is important to provide knowledge for the parents, child-headed families, and children in schools. From a public health and clinical point of view this study supports the idea that early detection of a pre-hypertensive and hypertensive status in young children needs more attention and precise control to prevent the cardiovascular and other non-communicable diseases in Zimbabwean adulthood population. It was noted also that blood pressure increased with age between gender groups, therefore adverse consequences and problems of hypertension can be reduced by early detection and diagnosis of obesity and hypertension in children should be practiced.

\section{Recommendations}

Considering that elevated BP in children may lead to cardiovascular diseases development at a later stage in life; there is need for routine measurement of BP as part of physical examination in school children. This would assist in identifying children with elevated BP, with the objective of establishing correct intervention procedures.

\section{Acknowledgments}

We would like to thank the school authorities, families and pupils for their enthusiastic participation in the study. We extend our special thanks to the practicing nurse and the three final year students from the National University of Science and Technology for assistance taking and recording measurements. The authors declare no conflict of interest. The authors received no funding from an external source.

\section{References}

[1] MartôÂn-Espinosa N, DõÂez-FernaÂndez A, SaÂnchez-LoÂpez M, Rivero-Merino I, Lucas-De La Cruz L, Solera-MartõÂnez M, et al. (2017) Prevalence of high blood pressure and association with obesity in Spanish schoolchildren aged $4 \pm 6$ years old. PLoS ONE 12 (1): e0170926. doi: 10.1371 journal

[2] Kamath VG, Parthage PM, Pattanshetty S, Kamath A, Balakrishnan A, Mishra T, et al. Prevalence of hypertension in the paediatric population in Coastal South India. Aust Med J. 2010; 3 (11): 695-8.

[3] Vos LE, Oren A, Bots ML, Gorissen WH, Grobbee DE, Uiterwaal CS. Does a routinely measured blood pressure in young adolescence accurately predict hypertension and total cardiovascular risk in young adulthood? J Hypertens. 2003; 21 (11): 2027-34.

[4] Lane DA, Gill P. Ethnicity and tracking blood pressure in children. J Hum Hypertens. 2004; 18: 223e228.

[5] Longo D, Fauci A, Kasper D, et al. Harrison principles of internal medicine. 18th ed. Tehran: Andishe Rafiee; 2012. p. 439 .

[6] Raj M, Sundaram KR, Paul M, Deepa AS, Kumar RK. Obesity in Indian children: time trends and relationship with hypertension. Natl Med J India. 2007 Nov-Dec; 20 (6): 288-93.

[7] Bartosh SM, Aronson AJ. Childhood hypertension: An update on etiology, diagnosis and treatment. Pediatr Clin North Am 1999; 46: 235-52.

[8] Rosner B, Prineas RJ, Loggie JMH, Daniels SR. Blood pressure nomograms for children and adolescents, by height, sex and age, in the United States. J Pediatr 1993; 123: 871-86.

[9] Moore WE, Stephens A, Wilson T, Eichner JE. Body mass index and blood pressure screening in a rural public school system: The Healthy Kids Project. Prev Chronic Dis. 2006; 3 (4): A114.

[10] Sun SS, Grave GD, Siervogel RM, Pickoff AA, Arslanian SS, Daniel SR. Systolic blood pressure in childhood predicts hypertension and metabolic syndrome later in life. J Paediatr. 2006; 119 (2): 237-46.

[11] Tarlton PA. Prevalence of elevated blood pressure in Hispanic versus non-Hispanic $6^{\text {th }}$ graders. J Sch Nurs. 2007; 23 (1): 47-52.

[12] Kidy F, Rutebarika D, Lule SA, Kizza M, Odiit A, Webb EL, et al. Blood pressure in primary school children in Uganda: a cross-sectional survey. BMC Public Health. 2014; 14: 1223.

[13] Amusa LO, Goon DT. Blood pressure among overweight children aged 7-13 years in 10 rural communities in South Africa: The Tshannda Longitudinal Study. Pak J Med Sci 2011; 27 (3): 664-667. 
[14] Raj M, Sundaram R, Paul M, Kumar K. Blood pressure distribution in Indian children. Indian Pediatr. 2010 Jun; 47 (6): 477-85.

[15] Obesity Task Force, World Health Organization. Global Strategy On Diet, Physical Activity And Health: Obesity and Overweight. 2005 [Online]. Available:

http://www.who.int/hpr/NPH/docs/gs_obesity. pdf [2015, 25 October].

[16] Armstrong MEG, Lambert MI, Sharwood KA, Lambert EV. Obesity and overweight in South African primary school children-the Health of the Nation Study. SA Med J. 2006; 96 (5): 439-44.

[17] Reddy SP, Resnicow K, James S, Funani IN, Kambaran NS, Omardien RG, et al. Rapid increases in overweight and obesity among South African adolescents: comparison of data from the South African National Youth Risk Behaviour Survey in 2002 and 2008. Am J Publ Health. 2012; 102 (2): 202-68.

[18] Marfell-Jones M, Olds T, Stew A, Carter L. International standards for anthropometric assessment. The International Society for the Advancement of Kinanthropometry; Australia: 2006.

[19] Cole TJ, Bellizzi MC, Flegal KM, Dietz WH. Establishing a standard definition for child overweight and obesity worldwide: international survey. Br Med J. 2000; 320 (7244): 1240-3.

[20] Hari P, Bagga A, Srivastava RN. Sustained hypertension in children. Indian Pediatr 2000; 37: 268-74.

[21] Amusa LO, Mbhenyane XG, Toriola AL, Amey KA, Ndaba K, Monyeki KD. The prevalence of hypokinetic risk factors in rural South African children: The Tshannda Longitudinal Study. AJPHERD 2007; Supplement: 86-101.

[22] Monyeki KD, Kemper HCG, Makgae PJ (2005). The association of fat patterning with blood pressure in rural South African children: the Ellisras Longitudinal Growth and Health Study. Int J Epidemiol, 35 (1): 114-20.

[23] Makgae PJ, Monyeki KD, Brits JS, Kemper HCG, Mashita J. Somatotype and blood pres-sure of rural South African children aged 9-13 years: Ellisras Longitudinal Growth and Health Study. Ann Hum Biol, 2007; 34 (4): 240-51.

[24] Xi B, Zhang T, Zhang M, Liu F, Zong X, ZhaoM et al. Trends in Elevated Blood Pressure Among US Children and Adolescents: 1999 \pm 2012 . Am J Hypertens. 2016; 29 (2): 217 \pm 25 . doi: 10.1093/ajh/hpv091PMID: 26158854.

[25] Goma F M, Nzala S H, Babaniyi O, Songolo P, Zyaambo C, Rudatsikira E, Siziya S, and Muula AS.: Prevalence of hypertension and its correlates in Lusaka urban district of Zambia: a population based survey. Int Arch Med. 2011; 4: 34.

[26] Mostswagole BS, Kruger HS, Faber M, Van Rooyen JM, De Ridder JH. The sensitivity of waist-to-height ration in identify-ing children with high blood pressure. CVJ Africa, 2011; 22 (4): 208-11.

[27] Mkhonto SS, Mabaso MLH. Relationship between obesity and blood pressure in school-going adolescents in Limpopo Province of South Africa. J Obes Res Clin Pract, 2012; doi: 10.1016/j.orcp.2012.02.001

[28] Nur N, Cetinkaya S, Yilmaz A, Ayvaz A, Bulut MO, Sumer H. Prevalence of hypertension among high school students in a middle Anatolian Province of Turkey. Health Popul Nutr 2008;
26: $88-94$

[29] Kollias A, Antonodimitrakis P, Grammatikos E, Chatziantonakis N, Grammatikos EE, Ster-giou GS. Trends in high blood pressure prevalence in Greek adolescents. J Hum Hyper-tens, 2009; 23 (6): 385-90.

[30] Shahid A, Ramzan A, Mustufa MA, Nasim S, Pir-zada AG. Blood pressure, body mass index and waist circumference of school going children of Karachi. PakJ Med Res, 2010; 49 (4): $116-20$.

[31] Aounallah-Skhiri H, El Ati J, Traissac P, Romd-hane HB, Eymard-Duvernay S, Delpeuch F, et al. Blood pressure and associated fac-tors in a North African adolescent population. A national cross-sectional study in Tunisia. BMC Publ Health. 2012; 12: 98 .

[32] Tirosh A, Afek A, Rudich A, Percik R, Gordon B, Ayalon N, et al.. Progression of normotensive adolescents to hypertensive adults: a study of 26,980 teenagers. $J$ Hypertens, 2010; 56 (2): 203-9.

[33] Zardast M, Namakin K, Taheri F, et al. Prevalence of high blood pressure in primary school children in Birjand-Iran. Journal of Birjand University of Medical Sciences. 2013; 19: $61-8$.

[34] Falah A, Gachkar L, Faraji S. Evaluation of blood pressure in school children 11-7 years in Tehran in 2003. Journal of Zanjan University of Medical Sciences. 2003; 11: 43-8.

[35] Krishna P, Bajaj S, Thennarasu K, Desai N, Prasammakumar KM. Regional differences in the reference blood pressure in young Indians. Indian Pediatr 2007; 44: 921-923.

[36] Wolf-Maier K, Cooper RS, Banegas JR, Giampaoli S, Hense HW, Joffres M. Hypertension prevalence and blood pressure levels in 6 European countries, Canada, and the United States. JAMA 2003; 289: 2363-2369.

[37] Lei S, S-Yong YX, Xiao-Han D, Chang-Sheng C. Geographical differences in blood pressure of male youth aged 17-21 years in China. Blood Press 2004; 13: 169-175.

[38] Abdulle A, Al-Junaibi A, Nagelkerke N. High blood pressure and its association with body weight among children and adolescents in the United Arab Emirates. PLoS One. 2014; 9 (1): e85129.

[39] Pate RR, Mclver K, Dowda M, Brown WH, Addy C. Directly observed physical activity levels in preschool children. $J$ Sch Health. 2008; 78 (8): 438-44.

[40] Manu R, Sundaram KR, Paul M, Deepa AS, Ku-mar RK. Obesity in Indian children: time trends and relationships with hyperten-sion. Natl Med J India, 2007; 20 (6): 288-93.

[41] Taksande A, Chaturvedi P, Vilhekar K, Jain M. Distribution of blood pressure in school children in rural area of Wardha Dis-trict, Maharashtra, India. Ann Paediatr Card. 2008; 1 (2): 101-6.

[42] Flores-Huerta S, Klunder-Klunder M, Reyes DIC, Santos JI. Increase in body mass index and waist circumference is associated with high blood pressure in children and adolescents in Mexico City. Arch Med Res, 2009; 40 (3): 208-13.

[43] Sorof JM, Lai D, Turner J, Poffenbarger T, Portman RJ. Overweight, ethnicity, and the prevalence of hypertension in school-aged children. Pediatrics. 2004; 113: 475 182 . PMID: 14993537. 
[44] Riley M, Bluhm B. High blood pressure in children and adolescents. American Family Physician. 2012; 85: 693-700.

[45] National High Blood Pressure Education Program Working Group on High Blood Pressure in Children and Adolescents.
The Fourth Report on the Diagnosis, Evaluation, and Treatment of High Blood Pressure in Children and Adolescents Pediatrics 2004; 114; 555

/content/114/Supplement_2/555.full.html\#ref-list-1 